\title{
Workdays, in-between workdays and the weekend: a diary study on effort and recovery
}

\author{
Madelon L. M. van Hooff • Sabine A. E. Geurts • \\ Michiel A. J. Kompier • Toon W. Taris
}

Received: 10 April 2006 / Accepted: 12 January 2007 / Published online: 14 February 2007

(C) Springer-Verlag 2007

\begin{abstract}
Objectives Effort-recovery theory (Meijman and Mulder in Handbook of work and organizational psychology, Psychology Press/Erlbaum, Hove, pp 5-33, 1998) proposes that effort expenditure may have adverse consequences for health in the absence of sufficient recovery opportunities. Thus, insight in the relationships between effort and recovery is imperative to understand work-related health. This study therefore focused on the relation between work-related effort and recovery (1) during workdays, (2) in-between workdays and (3) in the weekend. For these three time periods, we compared a group of employees reporting relatively low levels of work-related effort ("low-effort group") and a group of employees reporting relatively high levels of work-related effort ("high-effort group") with respect to (1) activity patterns, (2) the experience of these activity patterns, and (3) health and well-being indicators.

Methods Data were collected among university staff members. Participants $\left(\mathrm{N}_{\text {high-effort group }}=24\right.$ and $\mathrm{N}_{\text {low- }}$ effort group $=27)$ completed a general questionnaire and took part in a 7-day daily diary study covering five weekdays and the following weekend. Differences between the two effort-groups were examined by means of analysis of variance.
\end{abstract}

M. L. M. van Hooff · S. A. E. Geurts · M. A. J. Kompier ·

T. W. Taris

Department of Work and Organizational Psychology,

Radboud University, Nijmegen, The Netherlands

M. L. M. van Hooff $(\square)$

TNO Quality of Life, P.O. Box 718,

2130 AS Hoofddorp, The Netherlands

e-mail: Madelon.vanHooff@tno.nl
Results Compared to the low-effort group, the higheffort group (1) engaged less often in active leisure activities during the week and worked more overtime in the weekend, (2) considered both work and home activities as more effortful, but not as less pleasurable, and (3) reported higher levels of sleep complaints (weekdays only) and fatigue, more preoccupation with work (weekdays only) and lower motivation to start the next workweek during the weekend.

Conclusions Work-related effort is associated with various aspects of work time and (potential) recovery time in-between workdays and in the weekend. High levels of work-related effort are associated with activity patterns that are less beneficial in terms of recovery, with higher effort expenditure during and after work time, and with diminished health and well-being.

Keywords Effort $\cdot$ Recovery $\cdot$ Diary study .

University staff

\section{Introduction}

Much research has shown that high levels of job demands are related to increased levels of physical and psychological health problems across time (e.g., De Lange et al. 2003). Despite this strong focus on the relations between job demands and health, relatively little attention has been paid to the psychological and physiological processes that may explain why health is adversely affected by high job demands. One notable exception is effort-recovery (ER) theory (Meijman and Mulder 1998; Geurts and Sonnentag 2006). ER theory argues that working inevitably requires effort as an 
appeal is made to workers' abilities and their willingness to dedicate these abilities to the work task. Expending effort at work ("work-related effort") produces two kinds of outcomes: the tangible result of work activities, i.e. a product or service, and the psychological and physiological "costs" or load reactions (e.g., fatigue) associated with working. These load reactions are usually short-lived and reversible: they disappear after respite from work. However, under certain circumstances the recovery process may be insufficient or inadequate, and then short-term workrelated load reactions may turn into adverse and more chronic health problems, such as prolonged fatigue, chronic tension, and sleep deprivation (Åkerstedt 2006; Härmä 2006; Sluiter et al. 2001; Van Hooff et al. 2005).

Recovery opportunities after work may be inadequate in terms of quantity (time) and/or quality. Recovery time may be insufficient in case of prolonged exposure to high demands, for instance, when workers continue to pursue job-related activities during non-work time (e.g., by working overtime) or engage in other demanding (e.g., domestic) activities. Recovery is particularly at stake when during private time an appeal is made upon the same psychophysiological systems that were activated on the job. The quality of recovery may be endangered when individuals' psychophysiological systems show prolonged activation even if not exposed to any special demands during the recovery period. This may happen when workers have difficulty to relax at home after a stressful working day. For example, Brosschot et al. (2005) showed that when workers worry in their private time about the past or upcoming working day, the psychophysiological systems that were activated on the job remain activated, thus impeding the recovery process (cf. Ursin and Erikson 2004). Due to repeated or prolonged activation of psychophysiological systems, these systems are in danger of chronic overactivity, producing lasting changes in homeostatic mechanisms (i.e., allostatic load, McEwen 1998). Consequently, these originally adaptive systems may start to malfunction by showing either hyperactivity (the systems fail to shut-off) or hypoactivity (the systems are not turned on when needed), constituting a serious health risk. For example, chronic stress may cause the immune system to be not sensitive enough (hypoactivity), allowing infectious agents (viruses and bacteria) to enter the body and cause infectious diseases. Alternatively, the system may become overreactive so that the immune system itself causes ill health (such as autoimmune diseases and allergic diseases, Clow 2001).
The present study

Effort and recovery are nowadays salient research topics (Zijlstra and Sonnentag 2006). The present study builds on and extends this body of knowledge in at least four regards:

Firstly, although the effort-recovery process is assumed to unfold on a daily basis, there is only a limited number of studies examining this process from such a day-to-day perspective (e.g., Cropley et al. 2006; Meijman et al. 1992; Rook and Zijlstra 2006; Sonnentag 2001; Sonnentag and Zijlstra 2006; Totterdell et al. 1995). The majority of research in this area still focuses on either cross-sectional or on global long-term relations between job demands, lack of recovery and health (e.g., Kompier 1988; Sluiter et al. 2001). Thus, in order to obtain more insight in de day-to-day relations between effort and recovery, the present study examines the relation between work-related effort and recovery on a daily basis, both during and after working time.

Furthermore, although weekends may offer important opportunities for recovery, they are hardly included in previous studies. Exceptions are Fritz and Sonnentag's (2005) diary study, which showed that well-being after the weekend was higher when individuals had engaged in social activities during the weekend. Also, Totterdell et al. (1995) reported that sleep, mood and social satisfaction were worse on the first rest day following work shifts in comparison with subsequent rest days. In a study among shift-working nurses, Rook and Zijlstra (2006) found weekends to be important for recovery as well. To increase the understanding of the weekend as potential recovery period, the present study also included the weekend.

Thirdly, only limited attention has been given to actual activity patterns during work and non-work time in research on effort and recovery until now (see for exceptions: Fritz and Sonnentag 2005; Sonnentag 2001; Sonnentag and Bayer 2005). This is remarkable, as several work psychological theories (e.g., action theory, Frese and Zapf 1994; Taris and Kompier 2005) assume that job characteristics affect worker well-being through worker behavior: it is what people do that makes them feel tired or enthusiastic. Thus, in order to fully understand effort-recovery patterns during and inbetween workdays, we must know how people spend their time on work as well as on home activities. Therefore, the present study provided a detailed assessment of employees' activity patterns during and in-between working time.

Finally, what can be a burden for one individual may constitute a pleasure to the other. Consequently, 
insight in activity patterns in the work and private domain is insufficient to fully understand workers' effort-recovery patterns, and preferably workers' experience of the time spent on (non)work activities must be examined in this context (see also the recommendations by Sonnentag 2001). Until now, the extent to which workers experience their daily work and home activities as effortful and/or pleasant has nonetheless remained largely ignored. Therefore, the present study provided a detailed assessment of how employees experience their activities during and in-between working time in terms of effort and pleasure.

We distinguished between workers who reported a relatively high level of work-related effort (i.e., who generally experienced their workdays as effortful) during a standard work week (further referred to as the "high-effort group") and workers who reported a relatively low level of work-related effort ("low-effort group"). This division of our sample was employed in order to maximize the contrast between the two subgroups in terms of reported effort. The two effortgroups were compared with respect to (1) activity patterns (i.e., the time spent on/frequency of engaging in work activities, domestic activities, active leisure, and passive leisure), (2) experiences of activities (i.e., the specific effort and pleasure experienced while engaging in a specific work or home activity), and (3) health and well-being indicators (i.e., fatigue, sleep quality, sleep time, preoccupation with work, and work motivation). Fatigue is included an indicator of (lack of) recovery. As sleep provides the most "natural" recovery opportunity for humans, sleep quality and sleep time are incorporated as well (Åkerstedt 2006). Preoccupation with work is assessed, because it may prolong physiological activation and therefore interfere with the recovery process (Brosschot et al. 2005). Finally, to avoid focusing exclusively on the "negative" consequences of working, work motivation is added in this study to acknowledge that work may be related to positive aspects of worker behavior as well. These constructs were measured in three time periods: (1) during work time, (2) in-between successive workdays, and (3) during the weekend. In order to minimize the amount of time elapsed between the occurrence and the reports of a certain activity or experience, we utilized a diary design covering five uninterrupted weekdays directly followed by two weekend days. In this vein, the risk of retrospection bias was reduced (Bolger et al. 2003).

This study examines three interrelated research questions:

1. How is work-related effort associated with (a) time spent on work activities, (b) experiences of work activities, and (c) health and well-being during the workday?

As the distinction between the two groups is based on employees' reports of work-related effort, we expect that the high-effort group will also report to have expended higher effort on (at least some of) the specific work activities compared to the low-effort group (Hypothesis 1a). Support for this hypothesis is important from the perspective of validation of the effort-measure used to differentiate between the two effort-groups.

As the high-effort group should have invested higher levels of effort during the work day than the low-effort group, we expect to observe higher levels of fatigue at the end of the workday (Hypothesis 1b) as well as a (stronger) increase in fatigue during the workday (Hypothesis 1c) in the first group. We do not hold a priori expectations concerning the experiences of pleasure associated with work activities and with respect to the time spent on and the frequency of engaging in each work activity.

2. How is work-related effort associated with (a) time spent on home activities, (b) experiences of home activities, and (c) health and well-being in-between successive workdays?

We distinguish among four categories of home activities, i.e. (1) domestic activities (e.g., household chores), (2) overtime work, (3) active leisure activities (e.g., exercising), and (4) passive leisure activities (e.g., reading for pleasure, watching TV, listening to music; see also Sonnentag 2001). The latter category is considered as "passive", whereas the other three categories of activities demand effort to some extent, and are therefore labeled as "active". Based on ER theory, it can be argued that our capacity to expend effort is limited, and that the more effort is expended at work, the less remains for home activities. Accordingly, the high-effort group is expected to spend less time on and to engage less often in active home activities, and consequently, will spend more time on and engage more often in passive leisure activities (Hypothesis $2 a)$. Because of the supposed limited amount of energy left in the high-effort group, we further expect that this group will experience engagement in active home activities as more effortful relative to the loweffort group (Hypothesis 2b). As we do not have a priori expectations regarding differences between the groups in the pleasure experienced in home activities, possible differences are examined in an exploratory fashion.

Further, we expect that those who have expended high effort on the job (high-effort group) will report higher levels of fatigue and more sleep complaints in-between 
workdays compared to the low-effort group (Hypothesis $2 c$ ). In order to obtain a full picture of the participants' recovery in-between workdays, sleep time is also examined. Finally, we assume that workers who have expended higher effort during working time, will also be more preoccupied with their job after work (Hypothesis 2d). This expectation is in line with Sonnentag and Bayer's (2005) finding that those who experienced high workload during the workday found it more difficult to detach from work during evenings than others. We do not formulate a priori expectations regarding possible differences in work motivation between the two effort-groups.

3. How is work-related effort associated with (a) time spent on home activities, (b) experiences of home activities, and (c) health and well-being during the weekend days?

The hypotheses formulated for the period in-between workdays (in "Research question 2") can be extended to the weekend. Hence, we expect that those who have spent high effort on the job during week days (the higheffort group), will-during the weekend-spend less time on and engage less often in active and will spend more time on and will engage more often in passive home activities (Hypothesis 3a), experience active home activities as more effortful (Hypothesis 3b), report more fatigue and more sleep complaints during the weekend (Hypothesis 3c), and will be more preoccupied with the upcoming workweek, than the loweffort group (Hypothesis 3d).

\section{Method}

\section{Participants and procedure}

This study was conducted in two stages among academic staff members of a medium-sized Dutch university. Of the 696 employees who were tenured and worked at least 3 days a week, only those could participate who (1) did not have a job outside this university (to keep the variation in work activities within acceptable limits), and (2) lived with a partner who worked at least 2.5 days a week (to increase the likelihood that the participants fulfilled at least some home obligations). Of the 146 employees who agreed to participate, $133(19 \%)$ completed a general questionnaire (first stage of the study). Data from 13 of these 133 were removed, as they apparently did not meet one or both of the selection criteria. To already reduce the influence of one possible confounder (i.e., working hours) of the associations between work-related effort and the variables of interest, this study was restricted to employees who worked at least 32 contractual hours a week. As a result, our sample comprised 93 employees (69.6\% male; $67.7 \% \geq 1$ child living in the household; $M_{\text {age }}=45.0$ years, $\mathrm{SD}=7.6 ; 49.5 \%$ was assistant professor, $16.1 \%$ associate professor, $12.9 \%$ full professor, $21.5 \%$ other jobs, e.g. researcher or lecturer). Due to strict privacy regulations, we did not know how many of the employees that were approached for participation in the study actually met our inclusion criteria (i.e. had no job outside the university and lived together with a partner who worked at least 2.5 days a week). Therefore, we do not have insight in how many employees were in fact eligible for participation in the study, meaning that the overall response rate and the representativeness of our sample are unknown.

In the second stage of this study starting about ten days after the completion of the general questionnaire, the daily variables of interest were assessed by means of short questionnaires that were completed three times a day, from Monday to Sunday: (1) a morning questionnaire (to be completed after awaking in the morning, between 7:30 and 8:30 a.m.), (2) an afternoon questionnaire (to be completed around 6 p.m.), and (3) an evening questionnaire (to be completed before bedtime, between 10 and 11 p.m.). Only diaries that were completed within an acceptable time range around the requested time were included in the final database. We thus removed morning questionnaires that were completed more than $2 \mathrm{~h}$ after awakening; afternoon questionnaires that were completed before 4:30 p.m., after 8 p.m., or less than $3 \mathrm{~h}$ after the morning questionnaires; and evening questionnaires that were filled in less than $2 \mathrm{~h}$ after the afternoon questionnaire or after 3 a.m. This procedure resulted in $76.2 \%$ valid morning diaries, $73.4 \%$ valid afternoon diaries, and $72.5 \%$ valid evening diaries.

Variables derived from the general questionnaire (general measures)

Job types included "assistant professor", "associate professor", "full professor", and "other", such as researcher and teacher. Age was measured in years; Gender was coded as "0" for "male" and " 1 " for "female". Parental status was coded as " 0 " for having no children living in the household and " 1 " for having at least one child living in the household. The last three variables are potential confounders in the relationships of interest and are therefore included as covariates in further analyses.

General fatigue was assessed with the ten-item fatigue assessment scale (Michielsen et al. 2003). An exemplary item is "I am bothered by fatigue" [1 
"(almost) never", 5 (almost) always"], with higher scores reflecting higher levels of fatigue $(\alpha=0.86)$.

Work engagement was measured with five items adapted from Rothbard (2001). An example is "When I am working, I often lose track of time" (1 "strongly disagree", 5 "strongly agree"; $\alpha=0.78$ ).

Job pressure was measured with five items from the job content questionnaire (Karasek 1985), that were rephrased as questions [e.g., "Do you have to work very fast?" 1 "(almost) never", 4 "(almost) always"; $\alpha=0.74]$.

Job control was measured with six items from Van Veldhoven et al. (2002). An exemplary item is: "Can you take a short break if you feel this is necessary?" [1 "(almost) never", 4 "(almost) always"; $\alpha=0.67]$.

Social support from colleagues [e.g., "My colleagues show their appreciation for the way I do my job", 1 "(almost) never", 4 "(almost) always"; $\alpha=0.86]$, and Social support from supervisor [e.g., "My supervisor shows her/his appreciation for the way I do my job", 1 "(almost) never", 4 "(almost) always"; $\alpha=0.90$ ] were both measured with four items adapted from Geurts et al. (1999).

Positive affect and negative affect were measured by means of the positive and negative affect schedule (PANAS; Watson and Clark 1988). Following Rothbard (2001), we distinguished between positive and negative affect regarding work and positive and negative affect regarding family. Sample items for negative affect are "upset" and "distressed", and examples for positive affect are "enthusiastic" and "proud" (1 very slightly or not at all, 5 extremely), with higher scores indicating higher negative or positive affect (negative affect: Cronbach's $\alpha=0.83$ for work and 0.84 for home; positive affect: Cronbach's $\alpha=0.87$ for work and 0.90 for home).

Life events Participants could report for ten events (e.g., birth of a child, financial troubles, change of job) whether or not they had experienced this event during the past year. The number of events experienced was summed.

Measures derived from the daily questionnaires (daily measures)

To limit the participants' burden, the questionnaires contained a combination of validated scales as well as single-item report-marks.

\section{Work-related effort}

In the afternoon questionnaire, participants were requested to indicate with a report mark the extent to which they considered the preceding workday as effortful (1 "not at all", 10 "extremely").

\section{Activities}

\section{Time spent daily on work activities}

Participants received a list of 13 major work activities and indicated the time (0 "none", 1 " $<1$ h", 2 " 1 $2 \mathrm{~h}$ ",..., and 7 " $>6 \mathrm{~h}$ ") they had spent on each activity during regular work time, i.e., until 6 p.m. (afternoon questionnaire), and during nonwork time, i.e., after 6 p.m. (evening questionnaire). We recoded this time range to obtain an estimate of the actual time in hours by assuming that the actual time spent on an activity would lie halfway the two extremes (e.g., the category " $<1$ h" was recoded as " 0.5 "). Time spent on research activities by day comprised the time spent on "conducting research", "data-analysis", "reading specialist literature", and "writing papers" (until 6 p.m.). Time spent on teaching activities by day included the time spent on "preparing a lecture", "giving a lecture", "reading (Ph.D.) students' assignments", and "appointments with (Ph.D) students" (until 6 p.m.). Time spent on administrative activities by day consisted of time spent on "preparing a meeting", "attending a meeting" and "e-mail/phone". The category "informal contact with colleagues" was entered in the analyses separately. A 13th activity, "other", was not incorporated in further analyses, as on average only $0.42 \mathrm{~h}$ were devoted daily to these activities. All work activities are potentially relevant to all participants as in the Netherlands lecturers also have some research time, and researchers will usually also teach.

Overtime work was computed by summing the time spent on all 13 work activities after 6 p.m. (this university did not offer evening classes) during weekdays, and by summing the total time spent on work activities before and after 6 p.m. on Saturday and on Sunday.

\section{Time spent daily on home activities}

Participants indicated in both the afternoon (until 6 p.m.) and evening questionnaires (from 6 p.m.) the amount of time they spent that day on ten categories of home activities (largely based on those used in Sonnentag's (2001) diary study). Answer possibilities and recoding procedure were identical to those used for work activities. To ease interpretation of the categories, participants received examples of activities in each category. Time spent on domestic activities was calculated by summing the total time (i.e., before and after 6 p.m.) devoted each day to "household activi- 
ties", "doing odd jobs in or around the house", "doing the groceries", "care giving activities" and "businesslike activities". Time spent on active leisure activities comprised the total time spent daily on "physical activities", "creative activities" and "social activities". The total time spent on passive leisure activities was computed by summing the time devoted to these activities (e.g., reading for pleasure, watching TV, listening to music) before and after 6 p.m. The tenth category, "other", was omitted from further analysis as the mean time spent on these activities ranged from only $0.15 \mathrm{~h}$ on Saturday to $0.21 \mathrm{~h}$ during weekdays.

\section{Experiences}

Participants indicated for each engaged work and home activity, the extent to which they considered it as effortful and as pleasant (1 "not at all", 10 "extremely"). An estimate of the average daily effort and pleasure for each category of activities was obtained by computing a weighted mean score. Thus, the summed product of hours spent on each activity within a category and the effort (pleasure) experienced while executing the activity was divided by the total hours spent on the activities in the respective category. By employing such a weighted score, the time spent on an activity is controlled for, assuring that the effort (pleasure) score really reflects effort (pleasure).

\section{Health and well-being}

Fatigue at work (weekdays' afternoon questionnaire) was measured with eight items adapted from Van Veldhoven et al. (2002), for example "I felt tired mentally" (1 "not at all", 10 "extremely"). Participants rated each item twice: (1) with respect to the first hour of the workday (Cronbach's $\alpha=0.87$ ) and (2) with respect to the last hour of the workday (Cronbach's $\alpha=0.86$ ).

Fatigue was measured in the morning, afternoon and evening questionnaires. Participants rated their current state of fatigue ("How fatigued do you currently feel?") with a report mark varying from " 1 " ("not at all") to "10" ("extremely").

Sleep complaints (each morning questionnaire) were assessed using a five-item sleep quality scale (Van Veldhoven et al. 2002), slightly adapted to make it suitable for day-to-day measurement. An exemplary item is: "Last night I woke up several times" (1 "yes", 0 "no", $\alpha=0.73$ across all seven consecutive days). Note that each day's values for this scale refer to the previous night.
Sleep time (each morning questionnaire) was computed by calculating the self-reported number of hours in-between the time they went to sleep last night ("what time did you go to sleep last night?") and the time they woke up this morning ("what time did you wake up this morning?"). Again, each day's values for this scale refer to the previous night.

Preoccupation with work (each morning questionnaire) was assessed with one self-developed item: "I am already mentally involved with the things I have to do at work today [next week]" (1 "not at all", 5 "extremely").

Work motivation (each morning questionnaire) regarding the upcoming workday (during weekdays) or the next workweek (during weekend-days) was assessed with one self-developed item: "I feel like starting the next workday [workweek]" (1 "not at all", 5 "extremely").

A table with correlations between the study variables can be obtained from the first author on request.

Figure 1 gives an overview of the measurement structure.

\section{Creation of the two effort-groups}

The global report mark for work-related effort as assessed in the afternoon questionnaire was used to create the two effort-groups. A workday was labeled as effortful if a report mark of six or higher was given. The number of effortful workdays was summed for each participant to obtain an estimate of how effortful he/she considered the workweek. To increase reliability only participants who gave a report mark during at least three out of the five possible workdays were selected, resulting in a final sample of 72 of the 93 original participants. The low-effort group $(n=27$; $\left.M_{\text {effort }}=3.39\right)$ consisted of participants who considered none (out of three) or only one workday (out of four or five) as effortful ( $>6)$. The high-effort group $\left(n=24 ; \quad M_{\text {effort }}=6.77\right)$ included participants who labeled two or three (out of three), three or four (out of four) or four or five (out of five) workdays as effortful.

\section{Statistical analyses}

Data were analyzed by means of (M)ANCOVA, which allows the examination of relationships between a categorical independent variable (the effort-subgroups) and continuous dependent variables (Maxwell and Delaney 2005). Gender, age, number of children in the household and number of contractual work hours (32 or more) were included as covariates in the analyses, because these may affect the relationships between 


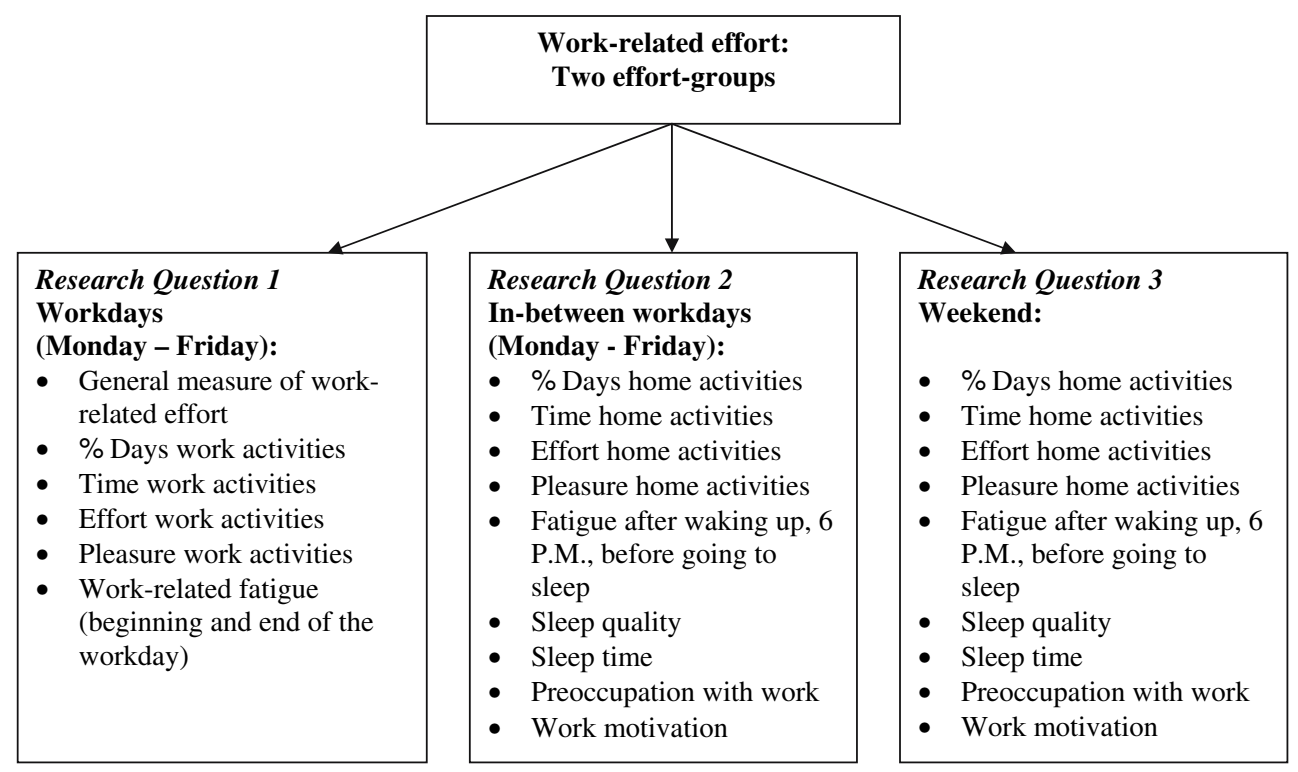

Fig. 1 Overview of the measurement structure

work-related effort and the other variables of interest in this study. One key assumption of MANCOVA is that the criterion variables are multivariately normally distributed (Maxwell and Delaney 2005). To examine whether this assumption could be maintained, the distributions of the criterion variables were inspected for univariate normality, both for the total sample and for the low and high effort subgroups. The skewness of the criterion variables was for 61 out of 64 variables in the study lower than 1.00. As this number is already expected on basis of chance, this finding suggests that the assumption of a multivariate normal distribution of the criterion variables could be maintained for practical purposes.

\section{Results}

Preparatory analyses

Table 1 shows the descriptive statistics for the general measures for the total sample as well as for the two effort groups. The total sample can be characterized as middle-aged, rather engaged, and not very tired. The mean level of fatigue in the sample does not significantly differ from that in a heterogeneous sample of 1,123 employees $(M=1.97, \mathrm{SD}=0.57, T(1214)=1.29$, ns; Geurts et al. 2005). Participants report relatively high levels of work pressure and job control. Levels of job control are higher than those in a heterogeneous

Table 1 Means and standard deviations for the total sample and for the two effort-groups for the measures derived from the general questionnaire

\begin{tabular}{|c|c|c|c|c|c|c|}
\hline & \multicolumn{2}{|c|}{ Total sample $(N=93)$} & \multicolumn{2}{|c|}{ Low-effort group $(N=27)$} & \multicolumn{2}{|c|}{ High-effort group $(N=24)$} \\
\hline & $M$ & SD & $M$ & SD & $M$ & SD \\
\hline Age & 44.95 & 7.63 & 46.74 & 6.69 & 44.17 & 7.80 \\
\hline Work engagement & 3.94 & 0.69 & 3.92 & 0.63 & 4.05 & 0.67 \\
\hline Fatigue & 1.89 & 0.61 & 1.87 & 0.57 & 2.04 & 0.60 \\
\hline Work pressure & 2.47 & 0.54 & 2.23 & 0.53 & 2.49 & 0.60 \\
\hline Job control & 3.22 & 0.42 & 3.25 & 0.46 & 3.30 & 0.39 \\
\hline Social support colleagues & 2.59 & 0.65 & 2.62 & 0.53 & 2.60 & 0.66 \\
\hline Social support supervisor & 2.35 & 0.87 & 2.49 & 0.79 & 2.19 & 0.90 \\
\hline Positive affectivity work & 3.61 & 0.53 & 3.57 & 0.62 & 3.51 & 0.51 \\
\hline Positive affectivity home & 3.59 & 0.63 & 3.74 & 0.71 & 3.47 & 0.52 \\
\hline Negative affectivity work & 1.93 & 0.57 & 1.93 & 0.50 & 2.04 & 0.67 \\
\hline Negative affectivity home & 1.83 & 0.56 & 1.83 & 0.59 & 1.95 & 0.47 \\
\hline Life events & 1.98 & 1.53 & 2.04 & 1.34 & 2.17 & 1.81 \\
\hline
\end{tabular}


sample of 1,740 employees $(M=2.54, \mathrm{SD}=0.63$, $T(1831)=-10.29, P<0.001$; Geurts et al. 2005).

To investigate possible differences in the composition of the two effort-groups, these groups were compared with respect to the general measures. No significant differences were observed regarding age $(T=1.27$, $d f=49$, ns), gender $\left(\chi^{2}=0.07, d f=2, \mathrm{~ns}\right)$, parental status $\left(\chi^{2}=0.14, d f=1, \mathrm{~ns}\right)$, job type $\left(\chi^{2}=1.43, d f=3\right.$, ns), general fatigue $(T=-1.00, d f=49, \mathrm{~ns})$ and work engagement $(T=-0.72, \quad d f=49, \quad n s)$. Also, the MANOVA executed with respect to job characteristics (job pressure, job control, social support from colleagues and supervisor) was not significant, $F(4$, $45)=0.98$, ns. Furthermore, the groups report comparable levels of positive and negative affect (work: $T(49)=-0.71$, ns; family: $T(49)=-0.13, \mathrm{~ns})$ and positive affect (work: $T(49)=-0.39$, ns; family: $T(49)=$ 1.01, ns). Finally, the two effort-groups did not differ significantly regarding the number of life events experienced $(T(49)=-0.29, \mathrm{~ns})$. Thus, in sum, there were no significant differences between the two effort-groups with respect to the general measures.

\section{Differences between Saturday and Sunday}

Preliminary analyses showed that the variables under study did not differ significantly between Saturday and Sunday $(F$-values ranged from $F(1,27)=0.00$, ns for effort reported for active leisure, to $F(1,8)=1.95$, ns for effort reported for overtime work). Therefore, further analyses are based on mean scores across the two weekend days.

\section{Research question 1}

Table 2 presents the means, standard deviations and $F$ statistics for the daily variables for the total sample and for each of the two effort-groups. As to work activities, two analyses were conducted. First, for each participant the percentage of days on which time was spent on each work activity was computed. MANCOVA revealed that these percentages did not differ significantly between the two effort-groups. Secondly, for each participant we computed the mean time they spent daily on each work activity across the five weekdays. Again, MANCOVA did not reveal any significant difference between the two effort-groups. Thus, the two effort-groups did not differ significantly in their work activity patterns during the workday.

To study possible differences in experiences, two MANCOVA's were conducted, both based on mean scores across the five workdays. The first analysis revealed that the two effort-groups differed signifi- cantly in the average amount of effort reported with respect to the four work activities. Univariate tests showed that the high-effort group experienced each activity as more effortful (Hypothesis 1a supported). The second analysis revealed that the two effort groups did not differ significantly with respect to the pleasure they derived from their work activities.

Possible differences between the two effort-groups in fatigue at work were examined in a 2 (Time: first hour vs. last hour) $\times 2$ (Group: low vs. high effort) repeated-measures ANCOVA. The development of fatigue during the workday differed significantly between the two effort-groups (significant time $\times$ group interaction). Post-hoc analyses showed that there were no significant differences between the two groups in their level of fatigue during the first hour of the workday $(T=-1.20, d f=49, \mathrm{~ns})$. However, the high-effort group reported a significantly higher mean level of fatigue during the last hour of the workday $(T=-2.66$, $d f=49, P<0.05)$, indicating that the high-effort group reported more fatigue at the end of the workday (Hypothesis 1b supported), and showed a stronger increase in fatigue (Hypothesis 1c supported) during the workday.

In sum, the participants in the two effort-groups do not engage in different types of work activities, nor do they experience their work activities differently in terms of pleasantness. However, the high-effort group reports to spend significantly more effort on each of the work activities, experiences significantly higher work-related levels of fatigue at the end of the work day, as well as a stronger increase in fatigue during the workday.

Research question 2

Means, standard deviations and $F$-statistics are presented in Table 3 . As to home activity patterns, two analyses were performed. First, for every participant, we computed the percentage of workdays they spent time on each type of home activity (domestic, active leisure, overtime work, and passive leisure). For each of these activities, an ANCOVA was conducted. Results showed that the groups only differed significantly with respect to active leisure activities: whereas the high-effort group spent on less than half of the work days $(43 \%)$ time on this type of activities, the low-effort group spent on more than half of the work days $(62 \%)$ time on this type of activities. Secondly, we conducted four ANCOVA's based on each participant's mean time spent daily on each of the four activities during the five weekdays, but these revealed no differences between the two effort-groups. These results provide partial support for Hypothesis 2a by 
Table 2 Activity patterns, experiences and recovery indicators during the workday

\begin{tabular}{|c|c|c|c|c|c|c|c|c|c|}
\hline \multirow[t]{2}{*}{ Hypothesis } & & \multicolumn{2}{|c|}{$\begin{array}{l}\text { Total sample } \\
(N=93)\end{array}$} & \multicolumn{2}{|c|}{$\begin{array}{l}\text { Low-effort } \\
\text { group }(N=27)\end{array}$} & \multicolumn{2}{|c|}{$\begin{array}{l}\text { High-effort } \\
\text { group }(N=24)\end{array}$} & \multirow[t]{2}{*}{$F(d f)$} & \multirow[t]{2}{*}{$P$} \\
\hline & & $M$ & SD & $M$ & SD & $M$ & SD & & \\
\hline \multirow[t]{6}{*}{-} & \% Days & & & & & & & & \\
\hline & Multivariate & & & & & & & $1.29(4,42)$ & 0.29 \\
\hline & Research & 61 & 33 & 60 & 37 & 62 & 30 & $0.60(1,45)$ & 0.81 \\
\hline & Teaching & 75 & 30 & 67 & 37 & 79 & 27 & $3.33(1,45)$ & 0.07 \\
\hline & Administrative & 90 & 16 & 90 & 16 & 86 & 20 & $0.00(1,45)$ & 0.99 \\
\hline & Informal contacts & 55 & 33 & 55 & 33 & 55 & 30 & $0.32(1,45)$ & 0.57 \\
\hline \multirow[t]{6}{*}{-} & Time & & & & & & & & \\
\hline & Multivariate & & & & & & & $0.31(4,42)$ & 0.87 \\
\hline & Research & 1.5 & 1.3 & 1.7 & 1.5 & 1.6 & 1.3 & $0.29(1,45)$ & 0.59 \\
\hline & Teaching & 2.0 & 1.4 & 2.0 & 1.7 & 2.1 & 1.4 & $0.36(1,45)$ & 0.55 \\
\hline & Administrative & 1.9 & 1.0 & 1.9 & 1.2 & 1.7 & 1.0 & $0.02(1,45)$ & 0.90 \\
\hline & $\begin{array}{l}\text { Informal } \\
\text { contacts }\end{array}$ & 0.4 & 0.3 & 0.4 & 0.3 & 0.3 & 0.2 & $0.89(1,45)$ & 0.35 \\
\hline \multirow[t]{6}{*}{ Hypothesis $1 \mathrm{a}$} & Effort (1-10) & & & & & & & & \\
\hline & Multivariate & & & & & & & $9.94(4,29)$ & $<0.001$ \\
\hline & Research & 4.87 & 2.20 & 3.24 & 1.66 & 6.44 & 1.78 & $26.53(1,32)$ & $<0.001$ \\
\hline & Teaching & 4.47 & 1.76 & 3.24 & 1.49 & 5.87 & 1.22 & $29.59(1,32)$ & $<0.001$ \\
\hline & Administrative & 4.05 & 1.89 & 2.74 & 1.34 & 5.44 & 1.80 & $25.64(1,32)$ & $<0.001$ \\
\hline & $\begin{array}{l}\text { Informal } \\
\text { contacts }\end{array}$ & 2.60 & 1.48 & 1.85 & 1.18 & 3.30 & 1.62 & $7.76(1,32)$ & $<0.01$ \\
\hline \multirow[t]{6}{*}{-} & Pleasure (1-10) & & & & & & & & \\
\hline & Multivariate & & & & & & & $0.07(4,29)$ & 0.99 \\
\hline & Research & 7.18 & 1.09 & 7.14 & 1.37 & 7.23 & 1.05 & $0.00(1,32)$ & 1.00 \\
\hline & Teaching & 6.69 & 1.04 & 6.88 & 1.34 & 6.61 & 0.60 & $0.01(1,32)$ & 0.94 \\
\hline & Administrative & 5.76 & 1.52 & 5.94 & 1.46 & 5.92 & 0.91 & $0.02(1,32)$ & 0.89 \\
\hline & $\begin{array}{l}\text { Informal } \\
\text { contacts }\end{array}$ & 7.52 & 0.95 & 7.31 & 1.21 & 7.54 & 0.88 & $0.17(1,32)$ & 0.68 \\
\hline \multirow[t]{3}{*}{$\begin{array}{l}\text { Hypotheses } 1 \mathrm{~b} \\
\text { and Hypothesis } 1 \mathrm{c}\end{array}$} & $\begin{array}{l}\text { Health and } \\
\text { well-being }\end{array}$ & & & & & & & & \\
\hline & $\begin{array}{l}\text { Work-related } \\
\text { fatigue first hour }\end{array}$ & 1.89 & 1.03 & 1.69 & 0.65 & 1.96 & 0.91 & $\begin{array}{l}\text { Time: } 0.00 \\
(1,45) ; \\
\text { Group: } 4.63\end{array}$ & 0.96 \\
\hline & $\begin{array}{l}\text { Work-related } \\
\text { fatigue last hour }\end{array}$ & 2.56 & 1.30 & 2.13 & 0.86 & 3.00 & 1.43 & $\begin{array}{l}(1,45) \\
\text { Time } \times \text { group: } \\
6.09(1,45)\end{array}$ & $<0.05$ \\
\hline
\end{tabular}

$F$-statistics, $P$-values, and means and standard deviations for the total sample and for the two effort-groups

showing that participants in the high-effort group engage on average less often in active leisure activities.

In order to investigate possible differences in their experiences of home activities, two MANCOVA's were computed, both based on mean scores across the five weekdays. The first analysis showed an overall significant difference between the two effort-groups in the extent to which they considered home activities as effortful. Univariate tests demonstrated that the higheffort group considered active leisure activities and overtime work as more effortful (Hypothesis $2 b$ supported). The second analysis revealed that the two effort-groups did not differ significantly as to their pleasure regarding their home activities.

Regarding health and well-being, three analyses were conducted, each based on mean scores across the five workdays. For fatigue, a 3 (time: morning vs. afternoon vs. evening) $\times 2$ (group: low vs. high effort) repeated-measures ANCOVA indicated that fatigue did not vary significantly as a function of time. However, the two effort-groups did differ significantly in their average level of fatigue (main effect of Group). Post-hoc analyses demonstrated that the high-effort group reported higher levels of fatigue $(M=5.76)$ compared to the low-effort group $(M=3.89$, $T=-4.78, d f=49, P<.001 ;$ Hypothesis $2 \mathrm{c}$ supported for fatigue). The development of fatigue during the day did not vary significantly as a function of effortgroup (time $\times$ group interaction, ns). Furthermore, ANCOVA revealed that the high-effort group reported significantly more sleep complaints (Hypothesis 2c supported for sleep complaints). The third analysis (ANCOVA) showed that the two effort-groups did not differ significantly with regard to 
Table 3 Activity patterns, experiences, recovery indicators, work involvement and work motivation in-between workdays

\begin{tabular}{|c|c|c|c|c|c|c|c|c|c|}
\hline \multirow[t]{2}{*}{ Hypothesis } & & \multicolumn{2}{|c|}{$\begin{array}{l}\text { Total sample } \\
(N=93)\end{array}$} & \multicolumn{2}{|c|}{$\begin{array}{l}\text { Low-effort } \\
\text { group }(N=27)\end{array}$} & \multicolumn{2}{|c|}{$\begin{array}{l}\text { High-effort } \\
\text { group }(N=24)\end{array}$} & \multirow[t]{2}{*}{$F(d f)$} & \multirow[t]{2}{*}{$P$} \\
\hline & & $M$ & SD & $M$ & SD & $M$ & SD & & \\
\hline \multirow[t]{5}{*}{ Hypothesis $2 \mathrm{a}$} & \% Days & & & & & & & & \\
\hline & Domestic & 86 & 20 & 90 & 22 & 83 & 18 & $1.34(1,45)$ & 0.25 \\
\hline & Active leisure & 56 & 33 & 62 & 26 & 43 & 31 & $8.12(1,45)$ & $<0.01$ \\
\hline & Overtime & 49 & 23 & 43 & 27 & 58 & 34 & $4.92(1,45)$ & $<0.05$ \\
\hline & Passive leisure & 73 & 27 & 78 & 28 & 70 & 34 & $0.63(1,45)$ & 0.43 \\
\hline \multirow[t]{5}{*}{ Hypothesis $2 \mathrm{a}$} & Time & & & & & & & & \\
\hline & Domestic & 2.3 & 1.6 & 2.2 & 1.4 & 2.0 & 1.5 & $1.47(1,45)$ & 0.23 \\
\hline & Active leisure & 0.9 & 0.7 & 0.9 & 0.5 & 0.7 & 0.7 & $1.90(1,45)$ & 0.18 \\
\hline & Overtime & 0.9 & 0.8 & 0.8 & 0.7 & 1.1 & 1.0 & $2.42(1,45)$ & 0.13 \\
\hline & Passive leisure & 1.3 & 1.1 & 1.3 & 0.8 & 1.2 & 0.8 & $0.36(1,45)$ & 0.55 \\
\hline \multirow[t]{6}{*}{ Hypothesis $2 b$} & Effort (1-10) & & & & & & & & \\
\hline & Multivariate & & & & & & & $10.90(4,27)$ & $<0.001$ \\
\hline & Domestic & 2.96 & 1.57 & 2.46 & 1.22 & 3.32 & 1.76 & $0.80(1,30)$ & 0.38 \\
\hline & Active leisure & 3.58 & 1.76 & 2.91 & 1.36 & 4.56 & 1.99 & $7.24(1,30)$ & $<0.05$ \\
\hline & Overtime & 4.34 & 1.76 & 3.13 & 1.48 & 5.82 & 1.15 & $26.11(1,30)$ & $<0.001$ \\
\hline & Passive leisure & 2.06 & 1.24 & 1.50 & 0.82 & 2.81 & 1.58 & $3.37(1,30)$ & 0.08 \\
\hline \multirow[t]{6}{*}{-} & Pleasure $(1-10)$ & & & & & & & & \\
\hline & Multivariate & & & & & & & $0.67(4,27)$ & 0.62 \\
\hline & Domestic & 5.79 & 1.40 & 6.08 & 1.34 & 5.60 & 1.21 & $0.38(1,30)$ & 0.54 \\
\hline & Active leisure & 7.31 & 1.23 & 7.43 & 1.20 & 7.71 & 0.75 & $0.03(1,30)$ & 0.86 \\
\hline & Overtime & 6.34 & 1.29 & 6.33 & 1.49 & 6.16 & 0.95 & $0.07(1,30)$ & 0.80 \\
\hline & Passive leisure & 6.87 & 1.43 & 7.19 & 1.05 & 6.87 & 1.33 & $0.21(1,30)$ & 0.65 \\
\hline \multirow[t]{8}{*}{$\begin{array}{l}\text { Hypothesis } 2 \mathrm{c} \\
\text { and } 2 \mathrm{~d}\end{array}$} & $\begin{array}{l}\text { Health and } \\
\text { well-being }\end{array}$ & & & & & & & & \\
\hline & Fatigue $\mathrm{t} 1$ & 3.76 & 1.93 & 2.90 & 1.47 & 4.87 & 1.72 & $\begin{array}{l}\text { Time: } 2.16 \\
(2,44)\end{array}$ & 0.13 \\
\hline & Fatigue $\mathrm{t} 2$ & 4.92 & 1.74 & 3.90 & 1.56 & 5.88 & 1.40 & $\begin{array}{l}\text { Group } 22.46 \\
(1,45)\end{array}$ & $<0.001$ \\
\hline & Fatigue $\mathrm{t} 3$ & 5.71 & 1.98 & 4.87 & 2.07 & 6.52 & 1.50 & $\begin{array}{c}\text { Time } \times \text { group } \\
0.06(2,44)\end{array}$ & 0.95 \\
\hline & Sleep complaints & 1.54 & 1.12 & 1.25 & 1.00 & 1.95 & 0.95 & $4.12(1,45)$ & $<0.05$ \\
\hline & Sleep time & 7.09 & 0.88 & 6.85 & 1.05 & 7.13 & 0.70 & $1.85(1,45)$ & 0.18 \\
\hline & $\begin{array}{l}\text { Preoccupation } \\
\text { work }\end{array}$ & 3.32 & 1.00 & 3.19 & 0.90 & 3.75 & 0.95 & $4.41(1,45)$ & $<0.05$ \\
\hline & Work motivation & 3.40 & 0.70 & 3.49 & 0.85 & 3.21 & 0.50 & $3.00(1,45)$ & 0.09 \\
\hline
\end{tabular}

$F$-statistics, $P$-values, and means and standard deviations for the total sample and for the two effort-groups

sleep time. Concerning preoccupation with work, ANCOVA revealed that the high-effort group was significantly more preoccupied (Hypothesis 2d supported). A similar analysis conducted for work motivation did not reveal any significant differences between the two effort-groups.

In sum, the high-effort group engaged less often in active leisure activities in-between successive workdays, but did not differ significantly from the low effortgroup regarding the experience of pleasure associated with these activities. Further, the high-effort group experienced the home activities as more effortful. In addition, we systematically observed higher levels of fatigue; more sleep complaints, and a higher preoccupation with work in the high-effort group in-between workdays.
Research question 3

Table 4 presents the relevant means, standard deviations and $F$-statistics for the total sample and for the two effort-groups. To map possible differences in activity patterns between the two effort-groups, two analyses were conducted. First, we computed for each participant the percentage of weekend days on which time was spent on each home activity: The four ANCOVA's (one for each percentage) conducted for these percentage revealed no differences between both effort-groups. Secondly, with respect to the time spent on the four types of home activities, also for each activity an ANCOVA was conducted. Results revealed one important difference in activity patterns: the high-effort group spent significantly more time on overtime work 
Table 4 Activity patterns, experiences, recovery indicators, work involvement and work motivation during the weekend

\begin{tabular}{|c|c|c|c|c|c|c|c|c|c|}
\hline & & \multicolumn{2}{|c|}{$\begin{array}{l}\text { Total } \\
\text { sample } \\
(N=93)\end{array}$} & \multicolumn{2}{|c|}{$\begin{array}{l}\text { Low-effort } \\
\text { group } \\
(N=27)\end{array}$} & \multicolumn{2}{|c|}{$\begin{array}{l}\text { High-effort } \\
\text { group } \\
(N=24)\end{array}$} & \multirow[t]{2}{*}{$F(d f)$} & \multirow[t]{2}{*}{$P$} \\
\hline & & $M$ & SD & $M$ & SD & $M$ & SD & & \\
\hline \multirow[t]{5}{*}{ Hypothesis $3 a$} & \% Days & & & & & & & & \\
\hline & Domestic & 97 & 13 & 98 & 10 & 96 & 14 & $0.13(1,45)$ & 0.74 \\
\hline & Active leisure & 70 & 32 & 76 & 29 & 63 & 30 & $3.16(1,45)$ & 0.08 \\
\hline & Passive leisure & 87 & 26 & 85 & 27 & 79 & 33 & $0.27(1,45)$ & 0.61 \\
\hline & Overtime & 43 & 39 & 37 & 41 & 50 & 42 & $2.23(1,45)$ & 0.14 \\
\hline \multirow[t]{5}{*}{ Hypothesis $3 a$} & Time & & & & & & & & \\
\hline & Domestic & 5.0 & 2.4 & 5.0 & 2.0 & 5.3 & 2.5 & $0.14(1,43)$ & 0.71 \\
\hline & Active leisure & 2.5 & 2.0 & 2.4 & 1.6 & 2.4 & 2.6 & $0.11(1,43)$ & 0.74 \\
\hline & Passive leisure & 2.6 & 1.6 & 2.7 & 1.5 & 2.7 & 1.9 & $0.38(1,43)$ & 0.54 \\
\hline & Overtime & 1.2 & 1.4 & 0.8 & 0.9 & 1.4 & 1.7 & $6.14(1,45)$ & $<0.05$ \\
\hline \multirow[t]{5}{*}{ Hypothesis $3 b$} & Effort (1-10) & & & & & & & & \\
\hline & Domestic & 3.33 & 1.80 & 2.65 & 1.44 & 3.91 & 1.97 & $5.87(1,45)$ & $<0.05$ \\
\hline & Active leisure & 3.24 & 1.92 & 2.41 & 1.64 & 3.87 & 2.13 & $6.50(1,42)$ & $<0.05$ \\
\hline & Overtime & 4.54 & 2.01 & 3.42 & 1.72 & 5.49 & 1.80 & $9.01(1,24)$ & $<0.01$ \\
\hline & Passive leisure & 2.09 & 1.42 & 1.73 & 1.24 & 2.65 & 1.59 & $5.49(1,41)$ & $<0.05$ \\
\hline \multirow[t]{5}{*}{-} & Pleasure (1-10) & & & & & & & & \\
\hline & Domestic & 6.24 & 1.10 & 6.20 & 1.31 & 6.07 & 1.02 & $0.15(1,45)$ & 0.70 \\
\hline & Active leisure & 7.68 & 0.88 & 7.58 & 0.97 & 7.61 & 0.82 & $0.02(1,42)$ & 0.89 \\
\hline & Overtime & 6.03 & 1.57 & 6.28 & 1.78 & 5.96 & 1.25 & $0.58(1,24)$ & 0.45 \\
\hline & Passive leisure & 7.47 & 0.95 & 7.41 & 1.10 & 7.57 & 0.86 & $0.14(1,41)$ & 0.71 \\
\hline \multirow[t]{8}{*}{$\begin{array}{l}\text { Hypothesis } 3 \mathrm{c} \\
\text { and } 3 \mathrm{~d}\end{array}$} & $\begin{array}{l}\text { Health and } \\
\text { well-being }\end{array}$ & & & & & & & & \\
\hline & Fatigue (t1) & 3.43 & 2.10 & 2.69 & 1.69 & 4.00 & 2.24 & $\begin{array}{l}\text { Time: } 3.39 \\
(2,41)\end{array}$ & $<0.05$ \\
\hline & Fatigue (t2) & 4.26 & 2.04 & 3.56 & 1.64 & 4.72 & 2.21 & $\begin{array}{l}\text { Group: } 7.80 \\
(1,42)\end{array}$ & $<0.05$ \\
\hline & Fatigue (t3) & 5.69 & 2.09 & 4.56 & 2.19 & 6.38 & 1.57 & $\begin{array}{c}\text { Time } \times \text { group: } \\
0.15(2,41)\end{array}$ & 0.87 \\
\hline & Sleep complaints & 1.04 & 1.11 & 0.94 & 1.07 & 1.40 & 1.31 & $1.44(1,44)$ & 0.24 \\
\hline & Sleep time & 7.88 & 1.05 & 7.74 & 1.10 & 7.91 & 0.94 & $0.69(1,43)$ & 0.41 \\
\hline & Preoccupation work & 2.41 & 1.07 & 2.09 & 0.94 & 2.69 & 1.15 & $2.28(1,44)$ & 0.14 \\
\hline & Work motivation & 3.30 & 0.98 & 3.50 & 0.91 & 2.89 & 0.99 & $5.27(1,44)$ & $<0.05$ \\
\hline
\end{tabular}

$F$-statistics, $P$-values, and means and standard deviations for the total sample and for the two effort-groups

during the weekend compared to the low-effort group (Hypothesis 3a partially supported).

Conducting multivariate analyses for "pleasure" and "effort" would result in very restricted sample sizes ( $n=13$ in both groups). Therefore, only univariate tests were computed, revealing that the high-effort group considered all four activities significantly more effortful (Hypothesis 3b supported). Again, the two effort-groups did not differ significantly with respect to pleasure associated with their activities.

Three analyses were conducted to examine possible differences between the two effort-groups regarding health and well-being indicators. A 3 (time: morning vs. afternoon vs. evening) $\times 2$ (group: low vs. high-effort) repeated-measures ANCOVA revealed a main effect of Time. Post-hoc analyses indicated that fatigue increased significantly during the day, that is, was lowest in the morning $(M=3.32)$, somewhat higher in the afternoon $(M=4.08)$ and highest in the evening $(M=5.41)$.
Furthermore, overall, the two effort-groups reported different levels of fatigue (significant main effect of group). Post-hoc analyses showed that the high-effort group reported significantly higher levels of fatigue $(M=5.03)$ than the low-effort group ( $M=3.61$; Hypothesis $3 \mathrm{c}$ supported for fatigue). Finally, fatigue did not vary significantly between the effort-groups as a function of time of the day (non-significant time $\times$ group interaction). Two ANCOVAs indicated that sleep complaints and sleep time did not vary significantly between the effortgroups (Hypothesis $3 \mathrm{c}$ rejected for sleep complaints).

Two additional ANCOVAs indicated that the two effort-groups did not significantly differ with respect to preoccupation with work during the weekend (Hypothesis 3d rejected), but that the high-effort group felt less like starting the next working week (work motivation).

In sum, the two effort-groups did not show significantly different activity patterns during the weekend 
regarding domestic work, active and passive leisure. However, the high-effort group spent significantly more hours on overtime work during the weekend than the low-effort group. Furthermore, the high-effort group experienced all home activities as significantly more effortful, although not as less pleasant, than the low effort-group. We also observed significantly higher levels of fatigue during the weekend and less motivation to start the upcoming workweek in the high-effort group.

\section{Discussion}

The present study was devised to enhance our insight in the associations between work-related effort and recovery from that effort. To this purpose, we compared two groups of employees reporting different levels of work-related effort (high vs. low) with respect to their activities, experiences, and health and well-being in three time-periods: (1) during work time, (2) inbetween work days and (3) during the weekend.

\section{Activity patterns}

Our results revealed that the two effort-groups did not differ significantly in terms of their activity patterns at work. However, two significant differences were observed in the home domain. The first manifested itself in-between work days: the high-effort group performed active leisure activities on fewer days than the low-effort group, which is unfortunate, as active leisure activities seem to promote recovery (Sonnentag 2001).

A second difference appeared during the weekend. Contrary to our expectations (Hypothesis 3c), employees in the high-effort group spent more time on working overtime in the weekend. This implies that these employees devote part of potential recovery time during the weekend to activities that may interfere with the recovery process (cf. Sonnentag 2001).

The amount of time devoted to domestic activities during the weekdays and weekend days did not vary significantly between the two effort-groups. This may be due to the fact that many domestic activities are obligatory in nature (e.g., it is difficult to circumvent doing the household chores). Finally, no significant differences between the groups emerged concerning low-effort activities, both during weekdays and weekend days.

\section{Experiences}

Regarding experiences, we distinguished between effort and pleasure. The high-effort group reported significantly more effort for all work activities. In the home domain, the high-effort group judged overtime and active leisure activities as more effortful during weekdays and judged all activities as more effortful during the weekend. No significant differences between the groups were observed with respect to pleasure, neither during work time nor in-between workdays, nor in the weekend. Hence, work-related effort is independent of the pleasure derived from work and home activities.

\section{Health and well-being}

We observed a stronger increase in work-related fatigue during the workday for the high-effort group than for the low-effort group. Thus, whereas the two groups did not differ significantly in work-related fatigue at the start of the working day, the high-effort group was more fatigued at the end of the working day. This difference persisted in-between workdays. This finding might explain why the high-effort group engaged less often in active leisure in-between workdays than the low-effort group. Also during the weekend, the high-effort group remained significantly more fatigued than the low-effort group. Possibly, this may be due to the fact that the former group spent more time on overtime.

A somewhat different pattern of results was observed with respect to sleep complaints: The higheffort group reported more sleep complaints during the week, but not in the weekend. The additional finding that the two groups did not differ significantly with respect to sleep time suggests that work-related effort relates to sleep quality, but not sleep quantity.

During the week, the high-effort group was apparently more preoccupied with work than the low-effort group. However, it cannot be excluded that this is partly due to our item wording. Although we asked participants to indicate the extent to which they were already preoccupied with the upcoming workday, it would seem possible that this measure (also) reflects the extent to which participants were still ruminating about their past working day. In the weekend, the two groups did not differ significantly in their preoccupation with the upcoming workweek. This is surprising, as the high-effort group spent more time on work-related activities during these days. The high-effort group nonetheless reported less work motivation than the low-effort group.

\section{Limitations and suggestions for future research}

Six issues with respect to the present study must be discussed. First, as we employed a single item report mark 
to create the two effort-subgroups, the reliability and validity of this measure can be questioned. However, we believe that there are good arguments in favor of employing this report mark: (1) we did not rely on a single observation of this measure, as each participant completed the item on at least three occasions; (2) employees in the high-effort group considered each of the four categories of work activities as more effortful than the low-effort group, thus suggesting that the report mark correctly reflects the effort experienced during the workday; and (3) there is a correlation of $0.85(P<0.001)$ between our single-item effort-measure and a weighted mean score of the effort experienced during the separate work activities. The latter was computed by first weighting the number of hours spent on each activity by the effort expended to this activity; the sum of these weighted scores was divided by the total number of work hours. Thus, our singleitem report mark seems to measure a very similar quantity as a much more refined measure of effort.

A second point of concern is the procedure used to create the two effort-subgroups. These groups were created based on the number of days participants considered their work as effortful. To probe the possibility that our findings are biased by this somewhat arbitrary procedure we repeated our analyses using a slightly different effort indicator. For each participant who completed the report mark of global work-related effort on at least three occasions, the mean score on this report mark across the week was computed. Based on these scores, two new subgroups were created: One including participants with scores in the highest tertile, and a second with participants having scores in the lowest tertile. Analyses were repeated for these two groups, yielding results that were highly similar to those found for the original subgroups (results can be obtained from the first author on request). Thus, our findings appear robust across different measures of effort expenditure.

Thirdly, our study relied exclusively on self-report measures, and this might have resulted in an overestimation of the associations among the variables due to common method variance. However, this should have inflated all relations studied and not just part of these: the fact that some relationships were found while others were not, argues against the influence of common method variance in our study. Besides, alternative measures such as observational or physiological measures are not free of error variance either, and should therefore not be considered superior to self-report measures (Semmer et al. 2004; see also Kompier 2005). Furthermore, by demonstrating (1) that using selfreports does not guarantee finding significant results,
(2) that potential biasing variables (social desirability, negative affectivity and acquiescence) do not generally inflate correlations among study variables and (3) that monomethod correlations are not by definition higher than multimethod correlations, Spector (2006) concludes that "the popular position suggesting common method variance automatically affects variables measured with the same method is a distortion and oversimplification of the true state of affairs" ( $p$ 221). Thus, all in all we do not believe that common method bias severely biased our findings, although the use of physiological and performance measures in addition to selfreports could provide interesting insights in future research.

A fourth issue is the impact of potential third variables. One might argue that differences between the two effort-groups regarding (experiences of) activities and health and well-being indicators might be due to personality characteristics or other person or workrelated constructs, rather than to work-related effort. However, in our study we attempted to exclude the influence of these variables to our best ability: The two effort-groups turned out not to differ regarding the number of life events experienced, general work characteristics (work pressure, job control, social support), fatigue, work engagement, age and positive and negative affect. Of course this does not exclude the possibility that other third variables (e.g., other aspects of personality) may have acted as third variables in this study.

Fifth, this study did not offer insight in the intriguing question into the origin of the differences in workrelated effort between the two subgroups studied. It may be that these differences are at least partly due to differences in participants' objective work performance (e.g., number of publications or student evaluations), but such measure was not incorporated in this study. Thus, it is unclear how the differences between the two effort-groups in their work-related effort are related to real output differences, and future studies on this topic should also include objective measures of task performance.

Finally, the present research employed a very specific sample, consisting of academic staff members who worked at least $32 \mathrm{~h}$ a week and who lived together with a partner who worked at least 2.5 days a week, and who, as is common for tenured academics in the Netherlands, have relatively high job security and are not dependent on fund raising. Although we believe that our main findings on the relations among effort, recovery, health and well-being are not unique to this sample, it is desirable to replicate this study for employees in other professions, in other family 
situations and/or with other working hours. Thus, future studies should employ samples from other contexts to broaden our understanding of effort and recovery patterns.

\section{Assets of this study}

In spite of these limitations, we believe that the present study extends and enhances previous research on effort and recovery in at least four respects. First, this study is among the very few that examine effort and recovery from a day-to-day perspective, allowing us to demonstrate that work-related effort is related to various aspects of daily work and (potential) recovery time. In this vein, this study shows how effort expenditure at work is actually imbedded in everyday life, and how it relates to recovery during time-off-the job.

Secondly, this study emphasized the importance of the weekend as a (potential) opportunity for recovery. Whereas some differences between the two effortgroups persisted throughout the weekend (e.g., higher levels of fatigue and effort-investment for the higheffort group), other differences manifested themselves only during the working week (i.e., less active leisure, more sleep complaints and more preoccupation with work for the high-effort group) or only during the weekend (i.e., more overtime work and less work motivation for the high-effort group). Thus, not all workers employ the recovery opportunities offered by the weekend in a similar fashion: some seem to employ the weekend as a means to catch up with their overdue tasks. These results suggest that it would be worthwhile to study the reasons why workers differ in the way they use their weekend.

Thirdly, by paying attention to employees' activity patterns at work and outside work, we were able to show that effort expenditure at work relates to activity patterns in the home domain. Namely, high levels of effort expenditure at work were associated with less engagement in active leisure and more overtime work. This finding thus suggests that for some workers, high effort expenditure at work is not compensated by a corresponding degree of participation in recovery activities. Given that an imbalance between effort and recovery is associated with adverse health outcomes, this particular group of workers may, in the long run, be a risk group for the development of ill health.

Fourthly, we demonstrated that experiences associated with engagement in work and home activities are important: higher effort investment at work is related to experiences of higher effort expenditure outside work, but not to experiences of less pleasure regarding work or home activities.
Practical implications

Based on our study's results, three practical suggestions can be formulated. Firstly, adequate control opportunities in the job setting will allow workers to adjust their work behavior to their current need for recovery and, thus, to prevent the development of negative load reactions during working. Secondly, employees should be encouraged to engage in leisure activities that potentially contribute to the recovery process, such as active leisure. Finally, the time spent on overtime work should be kept within acceptable limits, as overtime work impedes the recovery process. Employers should not to demand excessive overtime work from their employees, in order to guarantee sufficient (potential) recovery time (see also Beckers et al. in press).

\section{Theoretical implications}

Our study revealed that workers who invest high effort at work differ in their off-the-job activity patterns from those who invest low effort at work: members of the first group are to a lesser degree engaged in active leisure during evenings in-between work days, and they spend more time on overtime work during the weekend. This different activity pattern may have consequences for the recovery process, as previous research suggests that active leisure promotes recovery, whereas overtime work impedes this process (Sonnentag 2001). That recovery is endangered in the high-effort group is also evidenced by the higher levels of fatigue during non-work time (evenings and weekends) and the lower sleep quality during the week. Apart from a different activity pattern, those expending high effort at work also expend high effort on home activities, which also may endanger the recovery process. Therefore, despite the fact that those investing high effort at work do not experience their activities as less pleasant than those expending low effort, they may be considered at risk for developing health problems in the long run.

Acknowledgments This study was supported by ASPASIA Grant \# 015.000.027 from the Netherlands Organization for Scientific Research (NWO) to Sabine Geurts. We thank Sabine Sonnentag and Jessica Rehe for their valuable input in this study.

\section{References}

Åkerstedt T (2006) Psychosocial stress and impaired sleep. Scand J Work Environ Health 32(6):493-501

Beckers DGJ, Van der Linden D, Smulders PGW, Kompier MAJ, Taris TW, Van Yperen NW. Distinghuising between overeen overtime work and long work hours among fulltimers and part-timers. Scand J Work Environ Health (in press) 
Bolger N, Davis A, Rafaeli E (2003) Diary methods: capturing life as it is lived. Annu Rev Psychol 54:579-616

Brosschot JF, Pieper S, Thayer JF (2005) Expanding stress theory: prolonged activation and perseverative cognition. Psychoneuroendocrinology 30:1043-1049

Clow A (2001) The physiology of stress. In: Jones F, Bright, J (eds). Stress. Myth, theory, and research. Prentice-Hall, Harlow,pp 47-61

Cropley M, Dijk D, Stanley N (2006) Job strain, work rumination, and sleep in school teachers. Eur J Work Organ Psychol 15(2):181-196

De Lange AH, Taris TW, Kompier MAJ, Houtman ILD, Bongers PM (2003) The very best of the millennium: Longitudinal research on the demand-control (-support) model. J Occup Health Psychol 8:282-305

Frese M, Zapf D (1994) Action as the core of work psychology: a German approach. In: Triandis, HC, Dunnette, MD, Hough, LM (eds) Handbook of industrial and organizational psychology, vol 4. Consulting Psychologists Press, Palo Alto, pp 271-340

Fritz C, Sonnentag S (2005) Recovery, health, and job performance: effects of weekend experiences. J Occup Health Psychol 10:187-199

Geurts SAE, Sonnentag S (2006) Recovery as an explanatory mechanism in the relation between acute stress reactions and chronic health impairment. Scand J Work Environ Health 32(6):482-492

Geurts S, Rutte C, Peeters M (1999) Antecedents and consequences of work-home interference among medical residents. Soc Sci Med 48:1135-148

Geurts SAE, Taris TW, Kompier MAJ, Dikkers JSE, Van Hooff MLM, Kinunnen UM (2005) Work-home interaction from a work psychological perspective: development and validation of a new questionnaire. Work Stress 19:319-339

Härmä M (2006) Workhours in relation to work stress, recovery and health. Scand J Work Environ Health 32(6):502-514

Karasek RA (1985) Job content instrument: questionnaire and user's guide. Department of Industrial and Systems Engineering, University of Southern California, Los Angeles

Kompier M (1988) Arbeid en gezondheid van stadsbuschauffeurs (Work and health of city bus drivers). Eburon, Delft

Kompier M (2005) Assessing the psychosocial work environment- "subjective" versus "objective" measurement (editorial). Scand J Work Environ Health 31:405-408

Maxwell SE, Delaney HD (2005) Designing experiments and analyzing data: a model comparison perspective, 2 nd edn. Erlbaum, Mahwah

McEwen BS (1998) Stress, adaptation, and disease: allostastis and allostatic load. Ann NY Acad Sci 840:33-44

Meijman TF, Mulder G, van der molen M, Cremer R (1992) Workload of driving examiners: A psychophysiological field study. In: Kragt W (ed.)

Meijman TF, Mulder G (1998) Psychological aspects of workload. In: Drenth, PJD, Thierry H, de Wolff CJ (eds) Handbook of work and organizational psychology, 2nd edn. Psychology Press/Erlbaum, Hove, pp. 5-33

Michielsen HJ, De Vries J, Van Heck GL (2003) Psychometric qualities of a brief self-rated fatigue measure: The fatigue assessment scale. J Psychosom Res 54:345-352

Rothbard NP (2001) Enriching or depleting? The dynamics of engagement in work and family roles. Admin Sci Quart 46:655-684

Rook JW, Zijlstra FRH (2006) The contribution of various types of activities to recovery. Eur $\mathrm{J}$ Work Organ Psychol 15(2):218-240

Semmer NK, Grebner S, Elfering A (2004) Beyond self-report: using observational, physiological, and situation-based measures in research on occupational stress. In: Perrewé PL, Ganster DC (eds) Research in occupational stress and wellbeing, vol 3. JAI, Amsterdam, pp 207-263

Sluiter JK, Frings-Dresen MH, Van der Beek AJ, Meijman TF (2001) The relation between work-induced neuroendocrine reactivity and recovery, subjective need for recovery, and health status. J Psychosom Res 50:29-37

Sonnentag S (2001) Work, recovery activities, and individual well-being: a diary study. J Occup Health Psychol 6:196-210

Sonnentag S, Zijlstra FRH (2006) Job characteristics and off-job activities as predictors of need for recovery, well-being, and fatigue. J Appl Psychol 91(2):330-350

Sonnentag S, Bayer UV (2005) Switching off mentally: predictors and consequences of psychological detachment from work during off-job time. J Occup Health Psychol 10:393-414

Spector PE (2006) Method variance in organizational research: truth or urban legend. Organ Res Methods 9(2):221-232

Taris TW, Kompier MAJ (2005) Job characteristics and learning behavior: review and psychological mechanisms. In: Perrewé PL, Ganster DC (eds) Research in occupational stress and well-being, vol 4. JAI, Amsterdam, pp 127-166

Totterdell P, Spelten E, Smith L, Barton J, Folkard S (1995) Revovery from work shifts: how long does it take? J Appl Psychol 80(1):43-57

Ursin H, Eriksen HR (2004) The cognitive activation theory of stress. Psychoneuroendocrinology 29:567-592

Van Hooff MLM, Geurts SAE, Taris TW, Kompier MAJ, Dikkers JSE, Houtman ILD, Van Den Heuvel FMM (2005a) Disentangling the causal relationships between work- home interference and employee health. Scand J Work Environ Health 31:15-29

Van Veldhoven M, De Jonge J, Broersen S, Kompier M, Meijman T (2002) Specific relationships between psychosocial job-conditions and job-related stress: a three level analytic approach. Work Stress 16:207-228

Watson D, Clark LA, Tellegen A (1988) Development and validation of brief measures of positive and negative affect: the PANAS scales. J Pers Soc Psychol 54:1063-1070

Zijlstra F, Sonnentag S (eds) (2006) Work and rest: a topic for work and organizational psychology (special issue). Eur J Work Organ Psychol 